patient I was asked to call at the house, and found him in great agony, complaining of pain all over the left side of his head, although there was no tenderness anywhere on palpation. There was complete anorexia and want of sleep, but there was no vomiting. He was ordered to bed, and a morphine draught given him. The local treatment of the affected ear was carried out every four hours until the discharge entirely ceased within a week's time. The ear was then syringed out night and morning.

On the third day of attendance severe rigors and shivering set in, followed by profuse perspirations, and these lasted for nearly a week off and on. Evidently meningitis had manifested itself, and for six weeks the temperature varied from $102^{\circ}$ to $104^{\circ}$ every day. There was general and intense headache, great throbbing in the blood vessels, much photophobia, restlessness, occasional sickness, and foul tongue; the pupils were normal. There was one particular symptom to be observed, and that was a constant twitching, although very slight, of the muscles on the left side of the face, and especially about the left nasal group, which evidently betokened some deep-seated irritation of the facial nerve. The patient was sensible, but got no sleep, except upon a strong hypodermic injection of morphine, which at first I gave night and morning; ice was applied to the head, and an occasional dose of calomel was taken. His symptoms began to improve, so that by November 22nd his temperature became normal; the skin was rather dry, the pulse rather tense and slow, but his tongue was still furred though more moist. The temperature remained normal night and morning, and he expressed himself as feeling very much better as regards the pain and throbbing in the head. I was in hopes that he might recover, and allowed him to leave his bed; but on the evening of November 26th he did not seem nearly so well, although his temperature was only $99^{\circ}$. He complained of violent pain at the back and left side of the head, also of giddiness. He wandered rather in his speech, and amongst other things he asked me "to send a message for him to the Queen." The morphine injection had been discontinued for three days, and I did not feel myself justified in administering any just then.

I called to see him early in the morning, and found him perfectly unconscious and breathing stertorously, which state had commenced and continued ever since 2 A.M. Thinking that probably the formation of a cerebral abscess was the cause of this sudden coma, I asked Mr. Richmond to see him in consultation with me, and we both agreed that although there were no distinct symptoms present which could point to the exact site of an abscess, yet still an exploration by means of trephining was the only remedy left, and was perfectly justifiable.

The parents consenting, and as their house was close by the local hospital, the patient was removed on a stretcher direct to the operating room, and trephining was performed at 2 P.M. by Mr. Richmond, surgeon to the Gravesend Hospital. The skull being exposed on the left side, the trephine was applied posterior to and a little above the external auditory meatus. The piece of bone being removed, the dura mater, which was normal but a little tense, was incised, and a hypodermic syringe was directed immediately downwards, when the point struck the petrous portion of the temporal bone, but without any result. The needle was then inserted directly inwards, when a small quantity of cerebral fluid escaped from the ventricle. An exploration being next made inwards, downwards, and a little backwards, a negative result ensued, and as the patient seemed in a very low state, operative measures were suspended. Dressings having been applied, he was removed to a ward, but died in the evening at 10 P.M., having never regained consciousness.

Next day a post-mortem examination was made at $2 \mathrm{P}$, the head only being examined. There were a few adhesions on removing the skull cap, and several nodules of fresh lymph were to be seen scattered along the superior longitudinal sinus, and especially about the torcular Herophili. There was no evidence of phlebitis.

On removing the brain, it was observed that there was no caries of the petrous bone present. Sections of the cerebral lobes showed them to be quite healthy. On making a section through the left hemisphere of the cerebellum, a small abscess cavity, containing about half an ounce of fotid pus, was discovered at its anterior and outer part. There was no very distinct lining to the cavity. The rest of the cerebellum was perfectly healthy.

REMARKS. -This case affords another example of an intracranial abscess, where it was difficult to diagnose its exact site, and even as to whether it was a cerebral or a cerebellar one. There was no paralysis, and the only prominent feature present was the constant twitching of the left facial muscles. In Dr. M. Foster's Physiology it is stated by Nothnagel that mechanical stimulation of even the surface of the cerebellum gives rise, without signs of pain being felt, to movements chiefly of the trunk and extremities of those muscles which are governed by the facial, hypoglossal, and fifth nerves. It might therefore be that the slight vibratory movements of the muscles in this patient's face were brought about by the formation of a small abscess in the left hemisphere of the cerebellum, and so causing irritation of that organ. What seemed to me curious in the symptoms was the decline of temperature during the last few days, as, with the presence of a presumable foul abscess, one might have expected high fever, but, nevertheless, the "dirty" tongue and high tension pulse pointed to some active mischief proceeding somewhere. I gather, in this particular case, that the ear trouble led to septic meningitis, and the latter tended to the formation of abscess; and it again shows the oft-repeated and frequently neglected necessity of treating all local discharges from the ear.

\section{A CONTRIBUTION TO THE STUDY OF} SULPHONAL.

BY JOHN GORDON, M.D.,

Physician, Aberdeen General Dispensary ; Assistant-Surgeon, Sick Children's Ilospital ; Assistant to Professor of Materia Medica, University of Aberdeen.

THE discussion which was opened by Professor Leech, of Manchester, at the annual meeting of the British Medical Association at Leeds in August, 1889, "On Recently Introduced Hypnotics and Analgesics," showed that sulphonal-one of the group-was on its trial. As might be expected, the results of the observations were conflicting, some having obtained good results. while others had been unable to obtain any marked benefit. It was elicited that in some cases a series of cerebral symptoms, such as giddiness, loss of co-ordination of the upper and lower extremities, states of expression and movement like those produced by alcoholic intoxication, sometimes followed the administration of the drug. Having recently undertaken a series of observations on the action of paraldehyde and urethane, which were published in this JOURNAL, I have made a like series of observations on the pharmacology of sulphonal.

Owing to the extreme insolubility of the drug in any neutral medium, considerable difficulty was experienced in some of the observations, and in the series of experiments on its action on muscle and nerve the solutions employed were saturated.

Sulphonal occurs in colourless crystals or as a white crystalline powder almost without taste or smell. It is comparatively insoluble in cold water, more soluble in boiling water, easily soluble in alcohol or ether, and it is not affected by acids or alkalies. Its solubility is slightly increased in the presence of sodium chloride; it can readily be given in hot tea or coffee, on thin bread and butter, or suspended by mucilage; but as it is nearly tasteless little or no aversion is offered to its exhibition. It is an oxidation product of the union of ethyl-mercaptan with acetone, its chemical nomenclature being diethyl-sulphon-dimethyl-methane, and its graphic formulæ may be represented thus:<smiles>CCOC(C)(C)O[R16](C)(C)CC</smiles>

It is thus a derivative of the alcoholic series from which other hypnotic agents, such as paraldehyde, methylal, etc., have been obtained. It was acimirably demonstrated by Dr. Lauder Brunton, in his fascinating and suggestive Croonian Lectures, that the possibilities of new therapeutic agents from this group by the process of substitution are infinite, and that it may be confidently expected that the series will yield a potent substance free from the disadvantages of those already discovered. Some of the objections to sulphonal are its insolubility, on which may depend its deferred hypnotic action, the time that elapses before the hypnotic action takes effect, the prolongation of the hypnotic action into the succeeding day, the giddiness, the loss of co-ordination of upper and lower extremities, depression of spirits, and cutaneous eruptions.

Action on Reflex Functions of the Spinal Cord.-A series of experiments were performed on frogs, to ascertain the action of the drug on the reflex functions of the spinal cord. The method em- 
ployed was to deceribrate a frog, waiting till the shock of the decerebration had been so far recovered from, to ligature the iliac artery of one limb, to suspend the frog by the head, allowing the hind limbs to depend, to immerse the hind limbs at the same moment in a solution of sulphuric acid ( 1 in 600 ), to record by a metronome the time of movement or withdrawal of the limbs from the acid solution, and to well wash the limbs in water after each withdrawal; when the time of withdrawal or movement was fairly equal in bcth limbs, to inject below the skin of the thorax a dose of sulphonal in a very fine state of subdivision, or to inject into the stomach of the frog the drug in a fairly divided condition, to wait for an hour or two, and to proceed with the immersions as before the administration of the drug. The result of a large number of these experiments proved that a longer period of time took place between the application of the stimulus and the reflex action after the administration of the drug. Sulphonal thus diminishes the excitability of the spinal cord, as also do paraldehyde and urethane. That sulphonal had an effect on the peripheral endings of the sensory nerves was shown by the elongation of the period at which the non-ligatured limb was either moved or withdrawn from the stimulus after the administration of the drug. Thus, as an example:

Decerebrated frog 32 grammes in weight: Left iliac artery and vein ligatured. Stimulation in бо $\mathrm{H}_{2} \mathrm{SO}_{4}$. Two decigrammes of sulphonal, in fine trituration, inserted into posterior lymph sac, and moistened with $\frac{3}{4}$ per cent. salt solution.

\section{Before Administration of Sulphonal.}

\section{LIGATURED LIMB.}

8 seconds, limb withdrawn.

5

Three Hoürs after Administration of $\stackrel{6}{2}$ decigrammes of S̈ulphonal. LigaTURED LiMB.

15 seconds, limb moved.

30 minutes later: 8 NLIGATURED LIMB.

8 seconds, limb moved. 6 seconds, limb moved.

8 seconds, limb moved 30 minutes later

15 seconds, limb moved. 30 minutes later

No movement.

30 minutes later.

15 seconds, limb moved feebly. No movement.

15 seconds, limb moved. 30 minutes later: 30 minutes later. $\mathrm{H}_{2} \mathrm{SO}_{4} \frac{3}{30}$ :

8 seconds, limb moved. $\quad$ No movement.

8 seconds, limb moved. 30 minutes later: 30 minutes later:

12 seconds, limb very feebly moved. No movement.

Action on Motor Nerves.-In these experiments the sciatic nerve of the frog was used to test the action on the conductivity of motor nerves. The solution employed was a saturated solution in $\frac{3}{4}$ per cent. solution of sodium chloride, and the apparatus employed was that devised by Professor Cash, and figured in the JounNat of November 2nd, 1889, in my paper on "Urethane." The result of a large number of experiments showed that the nerve trunk slowly lost its conductivity, and that subsequent washings with salt solution tended to recover it.

Action on Muscle Substance.-The experiments were performed on the gastrocnemii of the frog. The muscle was immersed in a solution contained in the muscle chamber invented by Professor Cash. Two sets of experiments were performed, namely, (1) the immersion of the muscle in a saturated solution, in a $\frac{3}{4}$ per cent. salt solution and single stimulations employed to test the irritability of the muscle substance, and (2) the immersion of the muscle in a saturated solution, in a 3 per cent. salt solution and the application of the faradic current to test the irritability of the muscle. The solubility of the drug at ordinary temperature in salt solution was but limited, the strength of the solution operated with being about 1 in 220. In all the experiments on muscle substance this saturated solution was employed, weaker solutions not seeming to offer any inducement to experiment with them. Since the action of salicylate of soda on frog muscle is negative, it was considered advisable to test the solubility of sulphonal in a solution of it, but it was found that its solvent power was not greater than that of sodium chloride.

(1) Result of single stimulations showed (a) that the solution slowly diminished the irritability of muscle substance; $(b)$ that after the muscle was washed in salt solution and immersed for a short time in it irritability was so far recovered; (c) that it was only after repeated poisonings and washings and immersions that the muscle failed to respond to electrical stimulation.

(2) Result of Faradic Current.-A saturated solution was employed for this method, and the experiment showed $(a)$ that there was a gradual lowering of the normal tetanic curve; $(b)$ that subsequent washings and immersion in salt solution recovered so far the muscular irritability, and it was only after prolonged treatment that the tetanic curve was abolished.

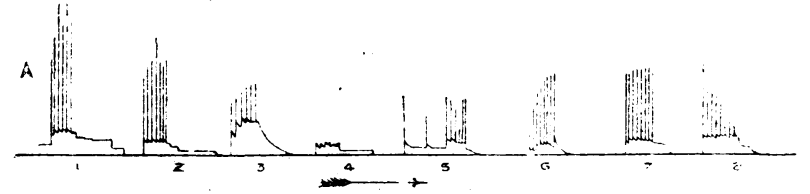

A, stimulation series. S. S. sulphonal in normal salt solution. Coil $=7.5$ centimetres.

I = normal stimuli.

II $=5^{\prime}$ later in sulphonal.

III $=5^{\prime}$ later in sulphonal.

IV $=5^{\prime}$ coil at 3.5 centimetres.

$\mathrm{V}=5^{\prime}$ imm. coil 3.5 centimetres, VI $=5^{\prime}$ after washing in salt solution. VI $=5^{\prime}$ coil 3.5 centimètres. $\begin{aligned} & \text { VII }=20^{\prime} \text { coil } 3.5 \text { centimètres. } \\ & \text { VIII }=30^{\prime} \text { coil } 0.0 \text { centimetre. }\end{aligned}$

Coil at 0.0 centimetre remained for $90^{\prime}$ with gradual loss of irritability, till at $180^{\prime}$ no response was obtained, coil being still at 0 .

Sulphonal thus resembles paraldehyde and urethane, so far as its action on muscle substance is concerned. All three drugs abolish temporarily the irritability of muscle substance. All allow of considerable recovery of the irritability of the poisoned muscle, if the muscle so poisoned be speedily washed in salt solution. It must be noticed, however, that the solutions of sulphonal employed in these experiments were far weaker than those of either paraldehyde or urethane. No initial rise in irritability was observed to follow the application of sulphonal; in this the drug resembled urethane and differed from paraldehyde.

Clinical Observations. - A number of experiments were conducted with the object of ascertaining the action of sulphonal on the excretions by the kidneys, comprising the increase or decrease of the fluid constituents of the urine, its action on urea, its influence on the excretion of phosphates, as well as its effect on the reaction of the urine.

Here let me thank the courtesy of a number of friends who willingly placed themselves at my service for these experiments. The experiments in all cases were fairly perfect and complete, and, as the results in each were much the same, one case has been selected and given complete. One case detailed is that of a boy aged 10, who was suffering from a slight attack of chorea, and on whom it was thought advisable to try the therapeutic action of the drug. The therapeutic action of the sulphonal on this case of chorea was negative. As it was evident from other observations that sulphonal had a marked hypnotic influence on persons in ordinary health, and as the object in this set of experiments was simply to ascertain its action on the excretions from the kidneys, the subject of the experiment was not confined to bed, but was allowed a moderate amount of exercise, the nature of which was fairly constant. The diet was regulated in regard to solids and fluids, and kept constant during the whole time of the experiment. The solids were weighed and the fluids measured, and the experiment was continued till the subject indicated that he was tired of it. In the case in which the drug was tried as a therapeutic agent in chorea, observations were also taken as to the action of the drug on the pulse, respiration, the skin, temperature, and digestion. When a fairly fixed average of excretions was reached a small dose of the drug was given for three consecutive mornings. This was followed by a like period of freedom from administration of the sulphonal, then three other days succeeded in which an increased dose was given, and so on, until the observations were concluded. A like method was employed while the chorea case was being treated. The total urine passed in twenty-four hours was collected, and its measurements are expressed in centimètres. The reaction was always noted on litmus paper immediately after the urine was passed. All the estimations of the urea and phosphates were checked by control experiments.

Diet.-The diets of the two recorded cases are given in full; the one, J. M., is that of the bay suffering from chorea, the other, J. C., is that of a healthy young man who placed himself at my disposal for the experiment.

Diet of J. M.-Case of Chorea.

The diet, which continued essentially the same during the whole experiment, was the following: 


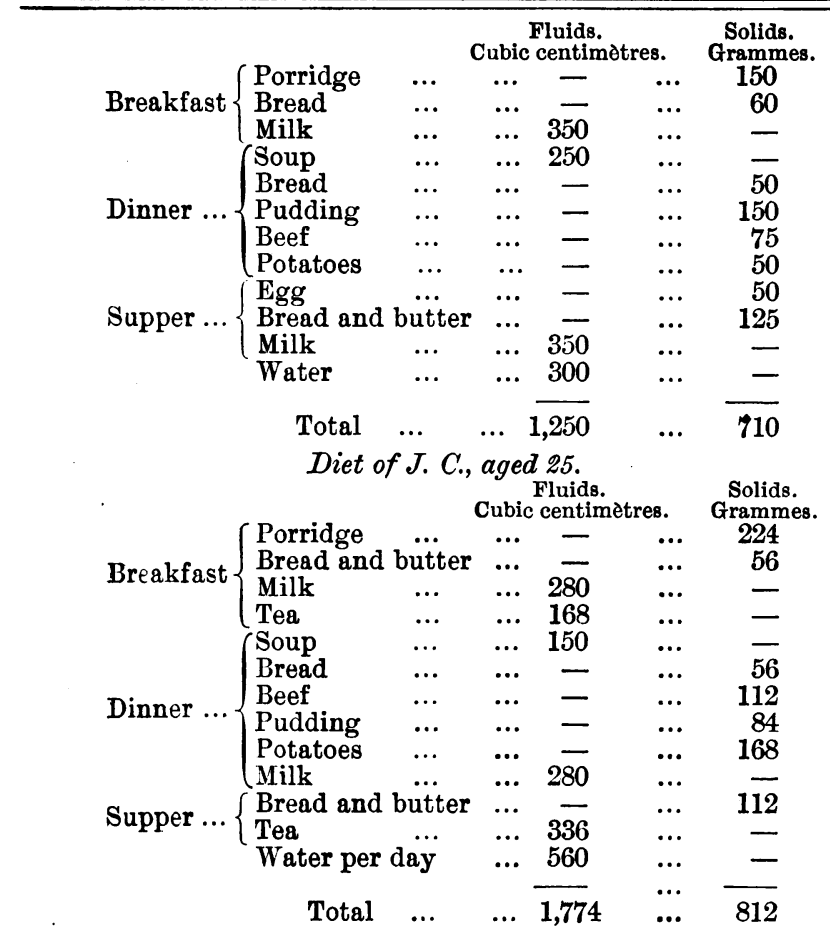

Estimation of Urea.-The method employed was that of Russel and West, that is, by decomposing the urea and calculating from the measured nitrogen the amount of urea present in the sample. This method, when employed with freshly prepared sodium hypobromate, is ready of application, and sufficiently accurate; care, however, should always be taken to allow a definite time for the nitrogen to pass into the graduated tube of the apparatus after the bulb has been warmed. This space of time was the same throughout the experiments, so that the result was equal in them all. The result of these observations showed that with small doses (5 to 10 grains) there was an increase in the excretion of urea, but that with large doses ( 30 to 40 grains) there was a decrease in the excretion.

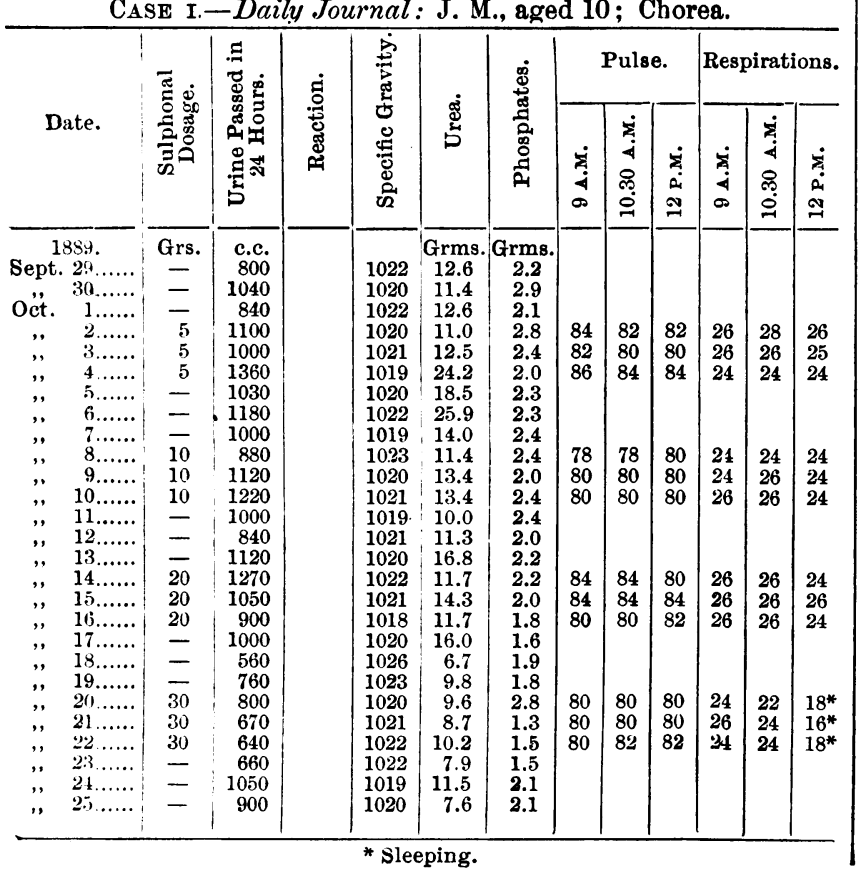

Taking the results obtained from the case of chorea, it was observed that with 5-grain doses there was an increase in the excretion of urea; thus the total excretion of urea for three days before the administration of the drug was 36.6 grammes; when, however, 5 grains were given for three consecutive days, the urea excreted amounted to $47.7 \mathrm{grammes}$, an increase of 11.1 grammes. Three days before the administration of 30-grain doses the total urea excreted was 32.5 grammes; when this dose was given daily for three consecutive days the total amount fell to 28.5, a decrease of 4 grammes. Again, the three days prior to the administration of 20 -grain doses, the total urea excreted was 38.1 grammes, and, with daily doses of 20 grains, the total urea excreted in three days was 37.7 , a decrease of 0.4 gramme. It was noticed that the controlling influence of the drug on the excretion of urea continued more or less for the three days succeeding the last administration of 30 -grain doses, the total amount of urea excreted being 27 grammes.

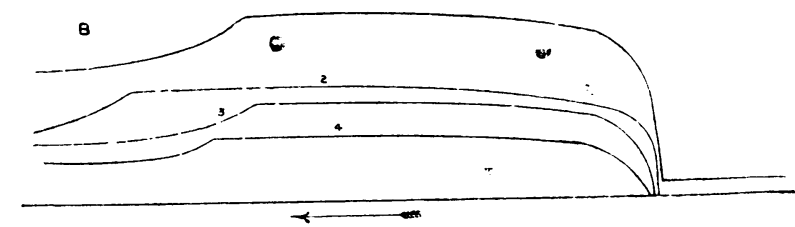

B. Faradic stimulation. $-30^{\prime}$ between each stimulation. S. S. sulphonal in normal salt solution.

Tracings show $I=$ normal tetanogram after $10^{\prime}$ in norm. salt. solu.

$" \quad$ II $=$ lowering after $30^{\prime}$ in sulphonal.

III = lower curve $30^{\prime}$ after last.

$\ddot{30}^{\prime}$ after IV = still greater lowering $30^{\prime}$ after III.

CASE Ir.-Daily Journal: J. C., aged 25 years.

\begin{tabular}{|c|c|c|c|c|c|c|}
\hline Date. & $\begin{array}{l}\text { Sulphonal } \\
\text { Dosage. }\end{array}$ & $\begin{array}{l}\text { Urine passed } \\
\text { in } 24 \text { hours. }\end{array}$ & Reaction. & $\begin{array}{l}\text { Specific } \\
\text { Gravity. }\end{array}$ & Urea. & Phosphates. \\
\hline 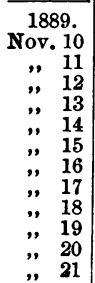 & $\begin{array}{c}\text { Grains. } \\
\overline{=} \\
\overline{20} \\
20 \\
20 \\
\overline{=} \\
\overline{40} \\
20 \\
20\end{array}$ & $\begin{array}{r}\text { c.c. } \\
1400 \\
1429 \\
1299 \\
1392 \\
1789 \\
1136 \\
1820 \\
1420 \\
1560 \\
1420 \\
1372 \\
1566\end{array}$ & 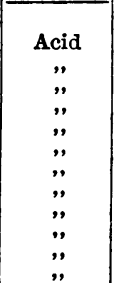 & $\begin{array}{l}1023 \\
1024 \\
1019 \\
1020 \\
1025 \\
1020 \\
1026 \\
1023 \\
1023 \\
1022 \\
1021 \\
1022\end{array}$ & $\begin{array}{c}\text { Grams. } \\
29.4 \\
32.8 \\
25.9 \\
27.8 \\
33.9 \\
24.9 \\
47.3 \\
34.0 \\
32.7 \\
31.2 \\
28.1 \\
26.0\end{array}$ & $\begin{array}{c}\text { Grams. } \\
5.0 \\
5.3 \\
3.6 \\
3.9 \\
4.5 \\
3.9 \\
4.7 \\
4.4 \\
4.6 \\
3.5 \\
3.7 \\
4.6\end{array}$ \\
\hline
\end{tabular}

In the case of J. C., aged 25 , for three days without the administration of sulphonal, the total amount of urea excreted was 88.1 grammes, and on three consecutive days, under the influence of sulphonal, with a dose of 25 grains daily, there was excreted 86.6 grammes, a decrease of 1.5 grammes. Again, in three days without sulphonal, there was excreted 114 grammes, and in three days with sulphonal in 30-grain doses daily, there was excreted 85.3 grammes, or a decrease of 28.7 grammes. It is thus evident that with doses sufficient to produce a hypnotic effect there is a decrease of the excretion of urea.

Estimation of Excretion of Phosphates. -The phosphates were estimated by a volumetric solution of uranium acetate, and in all these estimations control experiments were performed. The reaction on which the experiment depends is as follows:Uranium acetate with a soluble phosphate forms uranium phosphate, which is insoluble, and in a warm solution readily precipitated. Immediately on the whole of the uranium phosphate being precipitated, the termination of the reaction is indicated by means of potassium ferrocyanide, which gives a chocolate colour with soluble uranium compounds, this colour being due to the formation of uranium ferrocyanide.

The result of the experiments on the excretion of phosphates showed that sulphonal had a tendency to reduce their excretion. Thus, in the case of J. C., the total amount of phosphates excreted in three days without sulphonal was 13.9 grammes, while in the three succeeding days, with sulphonal in doses of 25 grains daily, the excretion of phosphates was 12.3 grammes, or a decrease with sulphonal of 1.6 gramme. And again, in three following days, no sulphonal having been given, the excretion of phosphates returned to 13.7 grammes, but when doses of 30 grains were given 
on the three succeeding days the excretion fell to 11.8 , decrease with sulphonal of 1.9 grammes.

Patting this another way; during six days during which no miphonal was given, the total amount of phosphates excreted wes 27.6 grammes, and in sir days, with daily odministration of sulphonal, the total amount of phosphate excreted whes 24.1 grammes, phonal, the decrease of 3.5 prammes in six days, which is a decrease of fully 0.5 gramme per diem. In another case, of which there are full records, the results are as follows:-

\begin{tabular}{|c|c|c|c|c|}
\hline & & $\begin{array}{l}\text { Phosphates } \\
\text { excreted. }\end{array}$ & Increase. & Decrease. \\
\hline $\begin{array}{c}\text { Three dass } \\
\text { ", } \\
\text { ", } \\
\text { ". }\end{array}$ & 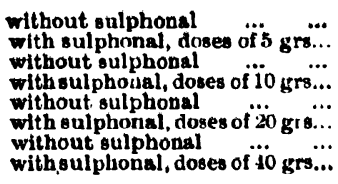 & 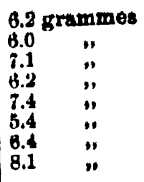 & $\begin{array}{l}= \\
= \\
\bar{z} \\
\overline{1.7}\end{array}$ & $\begin{array}{l}\overline{0.2} \\
\overline{0.0} \\
\overline{2.0} \\
=\end{array}$ \\
\hline
\end{tabular}

With regard to the last three days, it must be noticed that the average is increased by the extraordinary excretion that took place on the first of these three days during which the 40 -grain doses were given. This exceptional excretion of phosphates is difflcult to accnunt for, the subject being quite quiet, and showing no indication of restleseness. During the three days succeeding the administration of the 40-arain doses, the total excretion of phosphates was 5 grammes, indicating that the action of the drug in diminishing the excretion of phosphates still lingered.

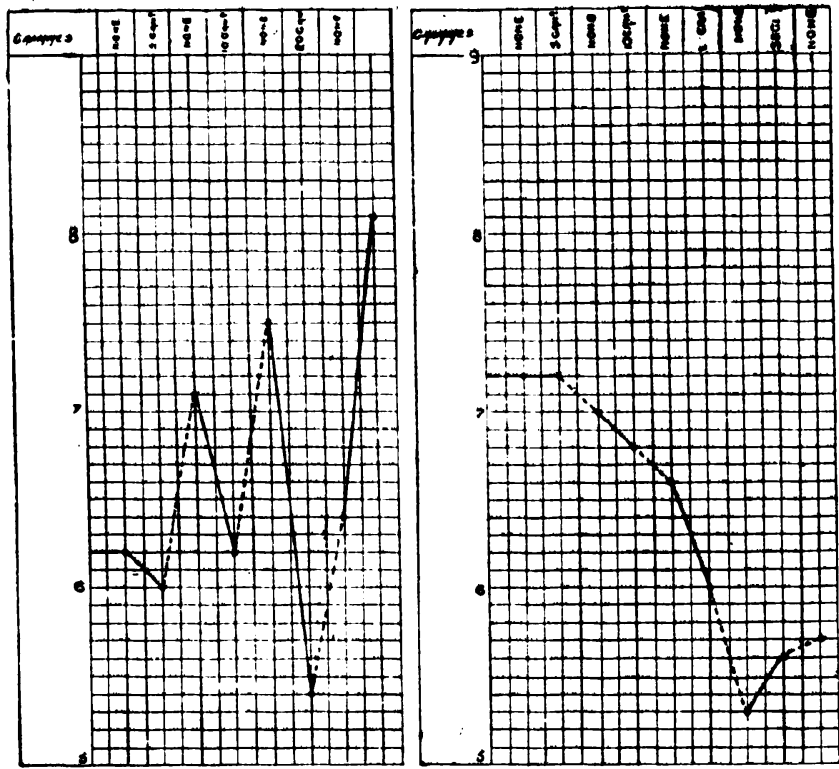

Phosphate charts.-Sulphonal given three consecutive days followed by three day' freedom. Phosphates expressed as total of three days (continuous line represents days on which drug was administered, interrupted line the days of non-administration). Quautities of phosphates expressed in grammes, doses of sulphonsl in grains.

Excretion of Fluid Constituents of Urine.-No deflnitely marked influence was observed to follow the administration of the drug as regards the fluid constituents of urine. With the smaller doses there was occasionally noticed a tendency to an increase, and with larger doses a decrease. Thus, in the case of J. M., the total quantity of urine passed in three days before the administration of sulphonal was 2,680 cubic centimetres, and the total quantity passed when 5 grains daily wers being administered was 3,460 cubic centimetres, or an increase of 780 cubic centimètres with sulphonal. The total quantity of urine passed in three days without sulphonal was 2,320 cubic centimetres, while under influence of daily doses of 30 grains the total quantity excreted in three days was $\mathbf{2 , 1 1 0}$, or a decrease with sulphonal of 210 cubic centimetres. The case of J.C. shows a like result. The total urine passed in three days before the administration of the drug was 4,128 cubic centlmatres, and, under influence of 25 -grain daily doses of sulphonal. the excretion was 4,317 cubic centimetres, or an increase with sulphonel of 289 cublc centimettres. Again the total urine paseced in three days without sulphonel was 4,800 , and in the three days, with daily doses of 30 grains, the total excretion of urine wees 4,358 cubic centimètres, or a decrease with sulphonal of 442 cubic contimotres. But the fluctuation of the fluid constituents of urine was too irregular to allow of any definite statement.

Reaction of Urine.-When the subjects were unier the influence of the drug, it was noticed that the reaction which was taken immediately after micturition was normally acid.

Colour and Odour also remained normal during the experiment, but with larger doses there were occasionally present urates in moderate quantities.

No albumen was over detected during any of the experiments.

Pulse, which was recorded before administration and at intervals of one, two, four, and sometimes six hours, or until the action of the drug seemed to have exhausted itself after administration, yielded negative results.

Respirations, which, like the pulse rate, were recorded at intervals, did not with the smaller doses show any alteration, but with large doses sufficient to produce the full hypnotic action there was a slowing of the respiratory acts to the extent of 2 to 6 per minute.

Action on the skin, both with small and large doses, was negative.

Temperature, which was taken during the experiment both in axills and rectum at stated intervals, was also negative.

Effects on Digestion. - Contrasted with paraldehyde and urothane, the action of sulphonal on the gastro-intestinal tract is diatinctly favourable. It was only at the end of the most prolonged experiment that in two or three cases any evidence of irritation was noticed. As in some cases the patient was on the same diet for month, certain reservation has to be made as to whether the drug was the entire cause of the disturbance two or three times noticed. The subject complained of sickness along with headeche and vomiting, which took place once or twice after a dose of 40 grains. It was noticed that, although emesis took place in both cases about six hours after dinner, the food was only very slightly digested. In another case it was observed that while the patient was having large doses there was a tendency to diarrhoe, the motions being large and loose. In none of these cases, however, did the subject complain of pain, nor was tenderness elicited by pressure on the stomach or bowels. In the majority of cases there was no interference with the action of the stumach or bowels, and the appetite remained perfectly good till the end of the experiment. This comparatively neutral action of the drug on the alimentary tract was still further confirmed by its exhibltion in those cases of insomnia where its use was indicated. None of the cases showed any tendency to have their gastric functions interfered with. No thirst was observed to follow administration.

Hypnotic Action.-Although the primary object of this section of the experiments was not to investigate the value of the drag as a hypnotic, still observations were noted regarding this action in some of the cases. In the case of cliorea the drug was given in the morning, the patient being kept in bed in a quiet room, 80 that if sleep should supervene there would be as few disturbing elements possible. Until doses of 20 grains were given, there was no hypnotic influence noticeable, but when this dose was reached the subject began to feel drowsy, and generally slept for an hour or two. When doses of 30 grains were given, the hypnotic action became still more marked, the patient remaining drowsy for most part of the day, with occasional sleeps intervening. On the third administration of 30 grains the boy slept most of the day, apparently pleasantly and contentedly, and there was no interference with his usual nightly sleep. The sleep was tranquil, refreshing, and only once did this patient aw with slight confusion of mind, and this was following the third 30-grain dose. Along with this confusion of thought there was giddiness and slight inco-ordination of the lower extremities. There can be no question that the drug has a valuable hypnotic action.

Clinical Observations in Cases of Insomnia.-From observations already recorded there cannot be any doubt that the drug is a valuable addition to the list of hypnotics. In the great majority of cases the sleep which follows the administration of the drug is freo from presomnial excitement, the sleep induced is tranquil, 
prolonged from six to ten hours, and the awakening is froe from unplessant sensations. There are cased, however, in which the administration of the drug produces certain sets of cerebral symptoms and distinct feelings of depression. No marked period of tolerance has been noticed, oven after considerable exhibition of the drug, and no distinct evidence of craving for the drug follows. As might be expected, the patient frequently desires a readministration of the dose where the insomnia has been overcome; but this feeling was more in apprehension of passing a sleopless night than from a morbid creving for the drug.

Owing to its insolubility many different methods have been proposed for its administration. Of the many methods probably the best is that the drug should be given in a state of the finest possible trituration in some warm inert fluid. In asylum practice it is common to give the drug in hot coffee, tea, or beer, and this, no doubt, is a distinct advantage, as the patient can be induced without suspicion to take what he considers is the ordinary beverage. It seems, however, from these observations that tea or coffee very considerably counteract the hypnotic action of the drug. For in the case of J. C., who was under observation, he was wrays able to modify the intense desire for sleep, which at times was very oppressing, by a cup of strong tea, and as a rule he stated that the sleepy feeling, once overcome by the tea, did not recur be fore the administration of another dose. It should be remembered, following its insolubility, that the drug must be given a considerable time, at least an hour, before it is desired to produce sleep, and that the patient should be placed in the most favourable condition possible to receive the greatest benefit from the drug. Contrasting its reliability with urethane and paraldehyde, it probably is the most valuable hypnotic. At any rate, over paraldehyde it has the great advantage of being tasteless and causing no after disagreeable odour of the breath. My friend Dr. George Duffus, of Parkside Asylum, Macclesfield, who kindly at my suggestion undertook a series of clinical observations, reports os follows: "An extended experience of sulphonal only confirms my early favourable impressions regarding it. It does not affect either respiration or circulation. I have used it in all sorts of cases, the weak and decrepit of 70 , and the robust of 25 . In a few caees sickness has come on, probably owing to some idiosyncrasy of the patient. A dose of less than half a drachm has never done any good; usually I give 40 grains, and in acute cases if the patient be fairly nourished a drachm is given. It acts more satisfactorily. and so far as $\mathrm{my}$ experience goes is tho best hypnotic wo possess. Dr. William Reid, of the Royal Lunatic Asylum, Aberdeen, who also kindly undertnok a series of clinical observations forme, report that the "effect of sulphonal as a hypnotic is eminently satisfactory," and he also regards it as the "best hypnotic we at present possess in insomnia of the insane." In cases of wasting diseasea, such as phthisis and tubercular disease of the joints, and also in some cases of hysteria, it was observed that occasionally a condition of depression more or less marked followed the dose, the patient frequently even complaining that he felt as if he were going to die. That this depression was cerebral was evident becruse the pulse kept quite good, and that it was due to the drug was fairly certain, since a repetition of the same dose produced a similar condition.

Tise drug being comparatively new, it is interesting and useful to notice that, in some cases at any rate, it produces symptoms which point to a distinct action on the cerebral functions, and it is well that these symptoms be carefully considered, so that a continued use of the drug may not lead to interference with mental coordination. In one case in which a dose of 40 graing had been given one night, and when only an hour or two of sleep was secured, a similar dose being given the night following, the patient slept for nearly sixteen hours. The sleep was tranquil, the patient could be easily roused, and made to answer intelligently ; the pulse continued normal. Respirations slowed 2 to 5 per minute. On getting out of bed on spontaneously awakening, he was unable to control his lower extremities, and could walk only with support. His limbs seemed to double up underneath him, and he complained of boing very giddy. On being helped to walk, there was a tendency to fall to the left side. The patient, indeed, presented all the pliysical appearances of one who, in a state of profound alcoholic intoxication, had retained intelligence. This condition of loss of power of the lower extremities and giddiness continued in a modihed degree for another day, and then gradually subsided without leaving any deleterious effect. Other cases akin to thed without ticed, although not to so marked a degree, giddiness and incoordination of the lower extremities being usually complained of.
In another case the inco-ardination was marked in the upper ar. tremitios alone. In this case the subject wes unsble to completely fulfil rolition with his hends : for example, when be wished to lift his teacup, he unconsciously let it drop in the act of conveying it from the saucer to bis mouth; and when this occurred sereral times, he was intensely surprised why it should happen. In some cases, again, complaint was made of confused sensations on awakening, the patients being nnable to undersitand who they were and where they were. So marked was thls in one case, that the patient preferred not to take another dose. This feeling of confusion in most cases speedily paesed away, but in one case it continued for about an hour and a half.

Its action on cases of acute alcoholism, sleeplessness being a prominent symptom, was tried, and the results in most of the cases were highly satisfactory. The dose given was from 60 to 80 grains; and although the action of the drug as a hypnotic was somewhat delayed, still the sleep which supervened was markedly refreshing. It was noticed in one case especially in which a combination of chloral bydrate and bromide of ammonis in large doses had not only failed to induce sleep, but was repeatedly vomited, a dose of 60 grains of sulphonal had the desired effect, producing eight hours of plessant sleep.

Slmarat of Ragults petarled in this Contribution. 1. It reduced the excitability of the reflex function of the spinal cord.

2. It diminished peripheral sensation.

3. Clinical observations showed that large doses slowed respiratory acts.

4. It did not affect the pulse rate.

5. That it slowly destroyed the conductivity of motor nerves, and that subsequent washingd with salt solution tended to restore it.

6. Saturated solutions slowly diminished irritability of muscle, but subsequent washings with salt solution tended to restore the irritability.

7. That small doses, 5 to 10 grains, increased excretion of urea.

8. That large doses diminished excretion of urea.

9. That under the influence of the drug the excretion of phosphates was diminished.

10. That it had no marked influence on the excretion of the fluid constituents of urine.

11. That in none of these experiments was any cutaneous eruption obeerved.

12. There was no flushing or perspiration markedly observed.

13. That its influence on temperature was negative.

14. That it occasionally caused vomiting, but there was no marked loss of appetite.

15. That diarrhoea was noticed occasionally.

16. That in good health a hypnotic effect was distinctly produced.

17. That in cases of insomnia it was reliable.

18. That the sleep which followed its administration was generally tranquil and refreshing.

19. That sometimes the patient woke with a feeling of confusion.

20. That inco-ordination of the upper extremities occurred occasionally.

21. That inco-ordination of the lower extremities occurred occasionally.

22. That a feeling of depression occasionally supervened.

23. That giddiness was observed.

In conclusion, I have pleasure in expressing my sincere thanks to Professor J. Theodore Cash for the use of his apparatus and laboratory.

New Method of Examining Negroda Tisboge in the Frash STate.-Kronthal (Neurologisches Centralblatt, No. 2, 1890) has described a method for examining in a fresh state the microscopical characters of the central nervous system. A piece-about as big as a pin's head $\rightarrow$ of brain or spinal cord, as the case may be, should be taken quite fresh and placed upon the object-glass. It is then covered with a cover-glass and pressed out flat. $\Delta$ drop of a 0.5 per cent. solution of methyl blue is placed at the edge of the cover-glass, which is raised to let the stain run in. After from thirty seconds to a minute the superfluous stain is removed with blotting-paper. The cover-glase is then raised; the preparation is allowed to dry in the air. This takes five or ten minutes. $A$ drop of Canada balsam is then added, and the preparation is ready for examination. 